\title{
IFITs: emerging roles as key anti-viral proteins
}

\section{Gregory I. Vladimer, Maria W. Górna and Giulio Superti-Furga*}

Laboratory of Giulio Superti-Furga, Center for Molecular Medicine of the Austrian Academy of Sciences, Vienna, Austria

\section{Edited by:}

Uday Kishore, Brunel University, UK

Reviewed by:

Andrew Tasman Hutchinson,

University of Technology Sydney, Australia

Mihaela Gadjeva, Harvard Medical

School, USA

Beatrice Nal, Brunel University, UK

*Correspondence:

Giulio Superti-Furga, Center for

Molecular Medicine of the Austrian

Academy of Sciences,

Lazarettgasse14, AKH BT 25.3,

Vienna 1090, Austria

e-mail: gsuperti-furga@

cemm.oeaw.ac.at
Interferon-induced proteins with tetratricopeptide repeats (IFITs) are a family of proteins, which are strongly induced downstream of type I interferon signaling. The molecular mechanism of IFIT anti-viral activity has been studied in some detail, including the recently discovered direct binding of viral nucleic acid, the binding to viral and host proteins, and the possible involvement in anti-viral immune signal propagation. The unique structures of some members of the IFIT family have been solved to reveal an internal pocket for nonsequence-specific, but conformation- and modification-specific, nucleic acid binding. This review will focus on recent discoveries, which link IFITs to the anti-viral response, intrinsic to the innate immune system.

Keywords: IFIT, innate immune system, anti-viral immune response, TPR, PAMPs

\section{INTRODUCTION}

The germline-encoded innate immune system initiates a fast and targeted response upon recognition of an invading virus. Most research on the innate immune system is focused on how the host senses and detects pathogen-associated molecular patterns (PAMPs), including viral nucleic acids. Foreign nucleic acid within the cytosol is an extremely potent PAMP, and the detection elicits a strong innate immune response (1). The host proteins that sense viral PAMPs, termed pattern recognition receptors (PRRs), range in their specific targets enormously and are located in endosomes and the cell cytosol (2-4). Some important PRRs that are specific to virus nucleic acid recognition include Toll-Like Receptors (TLRs) TLR3, TLR7, TLR8, and TLR9 $(4,5)$. Absent in Melanoma 2 (AIM2)-like receptors such as the AIM2 inflammasome and IFI16 (6-9), and RIG-I-like receptors including MDA5 (melanoma differentiation associated gene 5) and RIG-I (retinoic acid inducible gene I) $(10,11)$. The detection of various viral nucleic acid species by these receptors elicits signaling cascades that include the production of anti-viral genes and pro-inflammatory cytokines, including type I interferons (IFNs) (1). These responses slow virus replication by setting in motion a systematic anti-viral response.

Type I IFNs are comprised of IFN $\alpha$ and IFN $\beta$; these are responsible for an array of biological and immunological functions [reviewed in Ref. (12)]. Type I IFN signaling is mediated via the IFN $\alpha / \beta$ receptor (IFNAR), and downstream signaling results in the upregulation of IFN-stimulated genes (ISGs) (12). Beginning with the innate immune sensing of virus infection, ISGs encode many important protective and anti-viral pathways. ISGs are directly responsible for blocking virus infection and priming pro-inflammatory and adaptive immune response systems (12).

While the ISG class is quite large and diverse, this review will focus on a family of proteins that recently emerged as having a wide range of anti-viral functions: interferon-induced proteins with tetratricopeptide repeats (IFITs). The detection of virus infection by receptors and downstream pathways is of fundamental importance for our understanding of innate immunity processes regulating cellular homeostasis. Moreover, innate mechanism leading to inhibition of virus replication is particularly worth being investigated as they can possibly be harnessed for anti-viral therapy design.

\section{THE IFIT PROTEIN FAMILY}

The IFIT family includes four canonical human members (IFIT1, IFIT2, IFIT3, and IFIT5) and three mouse members (IFIT1, IFIT2, and IFIT3), which are induced upon simulation with IFN, virus infection, or other PAMP recognition $(13,14)$. Another human IFIT, IFIT1B, is thought to be expressed in a non-IFN dependent manner due to lack of an interferon-stimulated response element (ISRE), which typically are present in two to three copies within the promoters of the other IFIT genes $(15,16)$. IFIT5 is a paralog of IFIT1, which is absent in the murine genome. Instead, another closely related gene seems to be present in the mouse, Ifit 1c (17). Moreover, two additional genes, Ifit $1 b$ and Ifit $3 b$, are part of the mouse repertoire. IFIT homologs have been discovered in many vertebrate species: birds, fishes, and amphibians $(15,18)$. Their conserved role throughout evolution hints to their general importance. Since fish commonly contain multiple copies of IFIT genes that most resemble IFIT1/5, it is tempting to speculate that these IFITs are part of an ancient immune defense mechanism in vertebrates (19).

While IFITs generally are not expressed in cells at high basal levels, the transcription of IFIT genes rapidly increases during virus infection or IFNAR signaling (16). Low levels of IFIT5 expression, however, have been detected in HEK cells, which further increase several-fold upon IFN stimulation (13). The presence of the ISREs within the IFIT promoter region explains their low baselinetranscriptional levels and fast IFN-dependent induction (16). 
A

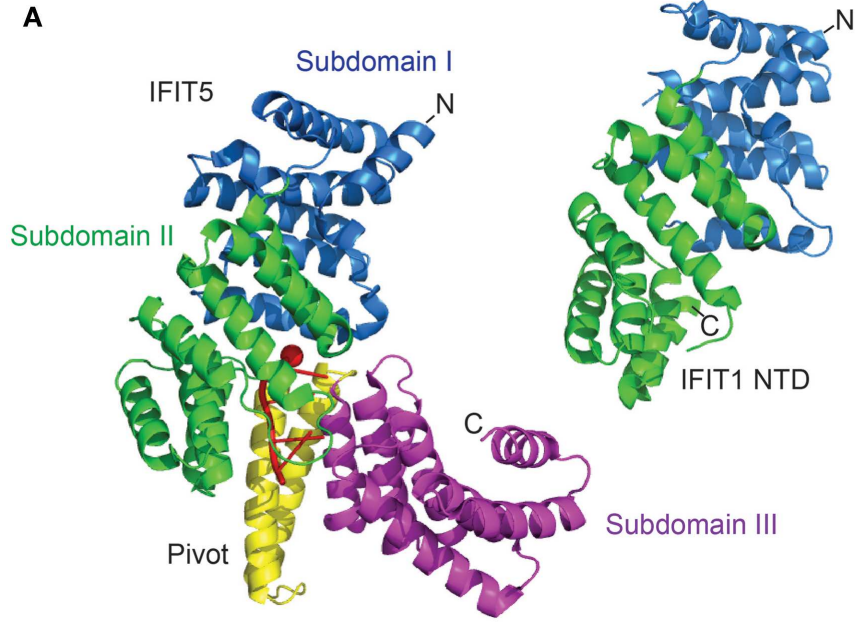

B

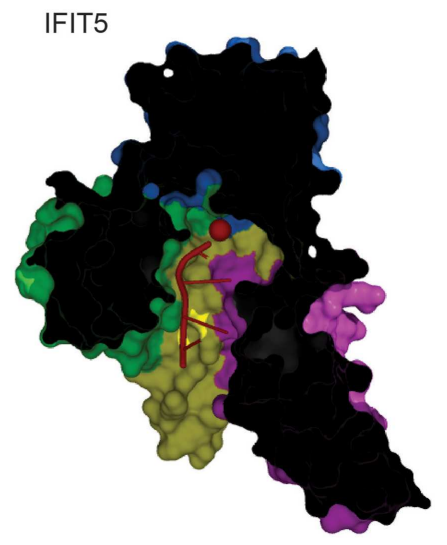

C

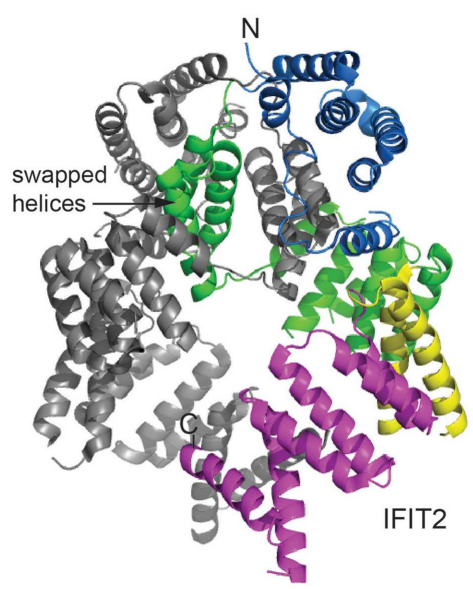

D

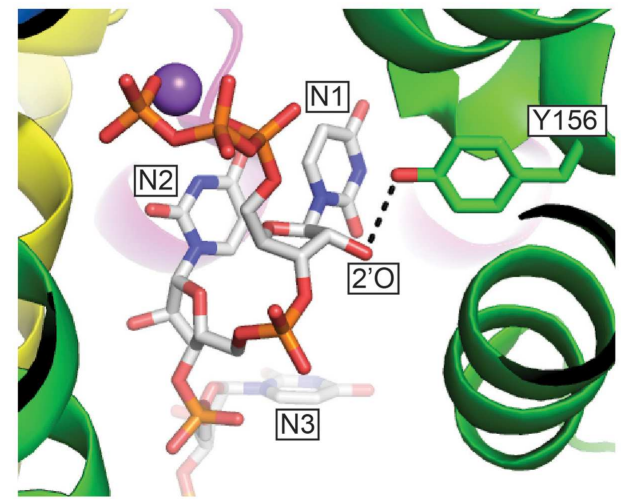

FIGURE 1 | (A) The structures of human IFIT5 in complex with oligoA and human IFIT1 NTD in cartoon representation (PDB entries 4HOT and 4HOU). The subdomains identified in IFIT5 are color coded, and RNA is in red. (B) Cross-section of the complex of IFIT5 with oligoA, showing a narrow pocket that binds four nucleotides. (C) The structure of human IFIT2 (PDB entry 4G1T) colored according to the corresponding IFIT5 subdomains. Indicated are helices 7-9 that are swapped with the other protomer. (D) The Y156 of IFIT5 forms a hydrogen bond (dotted line) with the 2'-O of the first ribose (IFIT5 in complex with oligoU, PDB entry 4HOS). Metal ions are depicted as spheres (Red, $\mathrm{Mg}^{2+}$; Purple, $\mathrm{Na}^{2+}$ ).
However, the kinetics of the transcriptional levels of specific IFITs can be cell line and tissue dependent $(20,21)$. Moreover, the transcriptional profile in different cell types could imply that specific IFITs have various functions during virus infections in the host.

\section{IFIT STRUCTURE}

All IFIT proteins consist of repeats of the eponymous tetratricopeptide (TPR) motif, which typically contains 34 amino acids with the consensus sequence [WLF]-X(2)-[LIM]-[GAS]-X (2)-[YLF]-X(8)-[ASE]-X(3)-[FYL]-X(2)-[ASL]-X(4)-[PKE] that adopts a basic helix-turn-helix fold. Adjacent TPR motifs usually form a sheet of antiparallel helices that curves into a super-helix, and this unique fold presents concave and convex curved surfaces that allow for binding of diverse ligands. TPR domains are conserved in all kingdoms of life and are generally believed to serve as protein and peptide recognition domains; with the discovery of RNA-binding IFITs, the known ligand spectrum of TPR motifs is broadened to also include nucleic acids.
The recent crystallographic structures of IFIT5 and the N-terminal half of IFIT1 (NTD) (22-24) reveal that the usual TPR super-helix is interrupted by an upside-down flip of the $\mathrm{N}$-terminal subdomain, but nevertheless the remainder of the protein forms a concave surface that binds the $5^{\prime}$ end of RNA (Figure 1A). The narrow pocket can accommodate up to four nucleotides of exclusively single-stranded RNA (Figure 1B), and the C-terminal subdomain tightens slightly around the aperture upon ligand binding. Most notably is the pocket that engages the $5^{\prime}$ triphosphate extension of the single-stranded RNA. Whereas, IFIT5 is monomeric, the structure of IFIT2 reveals a dimer (25), and IFIT1, IFIT2, and IFIT3 form homodimers in solution (13). The dimerization of IFIT2 occurs through swapping of three helices belonging to TPR motifs 3 and 4 (Figure 1C). IFIT2 might have a preference for double-stranded RNA (25), but it is not clear where the RNA-binding interface is located. With IFIT1 and IFIT5 targeting the $5^{\prime}$ end, and IFIT2 binding the body of the RNA, the IFIT proteins have diversified in the features of the non-self 
RNA that they recognize, described below, but it remains to be shown whether they complement each other and act in concert in a synergistic manner.

\section{IFIT ANTI-VIRAL FUNCTION}

Since IFITs are swiftly induced following virus infection, it is hypothesized that IFITs play a role in the anti-viral milieu of cells. Over the past years, many investigations have alluded to the important anti-viral mechanisms of each IFIT family member. Below, we will discuss the most important findings.

\section{5'-TRIPHOSPHORYLATED AND 2 ' - 0 -UNMETHYLATED CAPPED RNA BINDING}

In general, cellular cytoplasmic RNAs are single stranded and contain a $5^{\prime}$-monophosphate or N-7-methylated guanosine cap linked by a $5^{\prime}$-to- $5^{\prime}$ triphosphate bridge to the first base: rRNAs/tRNAs and mRNAs, respectively. In higher eukaryotes, mRNA is further modified with a methylated $2^{\prime}-O$ position of the first ribose (26, 27). These modifications and secondary additions assist in not only translational control, but the lack thereof plays a role in the detection of foreign nucleic acid. In contrast, viruses may form long double-stranded RNA, and/or generate triphosphorylated RNA (PPP-RNA) during their life cycle, which elicits a strong anti-viral response $(28,29)$. Using a proteomics approach, with PPP-RNA as bait, a mass spectrometry analysis revealed IFIT1 as a major binding partner in HEK cells (13); thereby revealing a role for IFIT1 in recognizing and potentially sequestering viral PPP-RNA, preventing it from being translated by the host machinery (Figure 2A). From the proteomic and subsequent biochemical analysis, it appeared as if only IFIT1 would bind the PPP-RNA directly while IFIT2 and IFIT3 bind IFIT1 in a multiprotein complex required for anti-viral activity (13). Knocking down IFIT1, IFIT2, and IFIT3 in HeLa cells with siRNA resulted in an increase rate of infection by viruses known to display a PPP-RNA nucleic acid species during their life cycle such as Rift Valley fever virus (RVFV), vesicular stomatitis virus (VSV), and influenza A. In contrast, growth of Encephalomyocarditis virus (EMCV), which does not produce a PPP-RNA species, was unaffected by the presence or absence of IFIT1 (13). Moreover, studies with IFIT $1^{-1-}$ mouse fibroblasts and myeloid cells also resulted in increased replication of VSV, with no changes detected in proinflammatory cytokines (13). Also, other studies determined that IFIT2 protects mice from VSV neuropathogenesis (30), and IFIT3 expression in human A549 cells is required for IFN $\alpha$-dependent anti-viral activity against VSV (31).

As described above, higher eukaryotes and many viral RNAs are not only methylated at the $N-7$ position, but also the $2^{\prime}-O$ of the $5^{\prime}$ guanosine cap. The lack of the latter cap, common for foreign nucleic acids, elicits a strong anti-viral response (32). Viruses lacking this $2^{\prime}$-O-methylation, such as a West Nile virus (WNV) that lacks $2^{\prime}$-O-methyltransferase activity, were unable to infect wild type cells, but could replicate in cells lacking IFIT1 expression $(33,34)$. Again, using proteomics, IFIT1 was discovered to have a much stronger affinity for $2^{\prime}-O$ uncapped vs. capped RNA, which explains the IFIT1 mediated control of $2^{\prime}-O$-methyltransferase deficient WNV (17). The study found that IFIT1 bound $2^{\prime}-O$ unmethlyated RNA, which resulted in an inhibition of translation, and therefore decreased virus infection (Figure 2A). Human IFIT5 has also been described to bind PPP-RNA (outside of the IFIT1IFIT2-IFIT3 complex), and also to uncapped $2^{\prime}$-O-unmethylated RNA $(13,17)$ (Figure 2A). IFIT1 binding of $2^{\prime}$ - $O$-unmethylated RNA was also supported by another study that described a role for IFIT1 in controlling Japanese Encephalitis Virus (JEV) $2^{\prime}$-MTase mutant by binding preferentially to capped $2^{\prime}-O$-unmethylated viral mRNAs (35).

IFIT1 can possibly accommodate capped RNA due to the larger size of the binding cavity. Mutagenesis of IFIT1 in the residue, which in IFIT5 makes contact with the $2^{\prime}-\mathrm{OH}$ of the first nucleotide (Figure 1D), followed by pulldowns on RNA, suggests that IFIT1 should be highly sensitive to the methylation status of this moiety (22), with methylated RNA being a poor ligand. Additionally, IFIT5 seems less sensitive to the disruption of $2^{\prime}-O$ binding, which enforces the notion of its high specificity for $5^{\prime} \mathrm{PPP}-$ RNA, since $2^{\prime}$-O-methylation usually occurs in conjunction with capping; there is also little evidence of sequence specificity in binding, as demonstrated by the structures of IFIT5 in complex with oligoU, oligoC, and oligoA (22). Furthermore, IFIT family members have been shown to effect translation by binding to mRNA with various $5^{\prime}$-modifications (36).

These studies nicely define a role for IFITs in the preferential binding to mis- or un-modified RNA in the cytoplasm; using a key evolutionarily conserved feature of transcriptional regulation to decipher self- vs. non-self nucleic acid.

\section{INHIBITION OF VIRAL PROTEIN TRANSLATION}

Eukaryotic cap-dependent protein translation relies on an $\mathrm{N}$ 7-methylguanoside cap at the $5^{\prime}$ end of mRNA, compared to the 5'-PPP-modified viral RNA species described above (37). Evidence has shown that IFIT family members can lessen host cap-dependent protein translation by binding to subunits of the eukaryotic initiation factor 3 (eIF3) translation complex (38) (Figure 2B). The eIF3 protein complex is required for translation initiation in several ways, including: mRNA recruitment, scanning mRNA for the start codon, and tRNA delivery to the translation machinery (37). Human IFIT1 and IFIT2 may perhaps block function of eIF3 tRNA delivery while human IFIT2 and mouse IFIT1 and IFIT2 may block mRNA recruitment (38-40). The decrease in mRNA translation can have detrimental effects on the host, though this also yields host-dependent virus replication. Viruses can also use internal ribosome entry sites (IRESs) during their replication for cap-independent translation, which also requires eIF3 (37). It was discovered that human IFIT1 can suppress this IRES-dependent viral RNA translation during Hepatitis $\mathrm{C}$ virus (HCV) infection (41). These studies, for which the molecular mechanism remains to be conformed, would suggest that IFIT family members may, on top of the indirect effects through RNA engagement, also affect virus translation directly, by altering translational processes itself.

\section{DIRECT VIRAL PROTEIN BINDING}

While it has become clear that IFIT mechanism of anti-viral activity is directed through binding foreign nucleic acid, yeasttwo-hybrid studies have suggested that IFITs can bind other viral proteins. IFIT1 binds to E1, a viral helicase from Human 

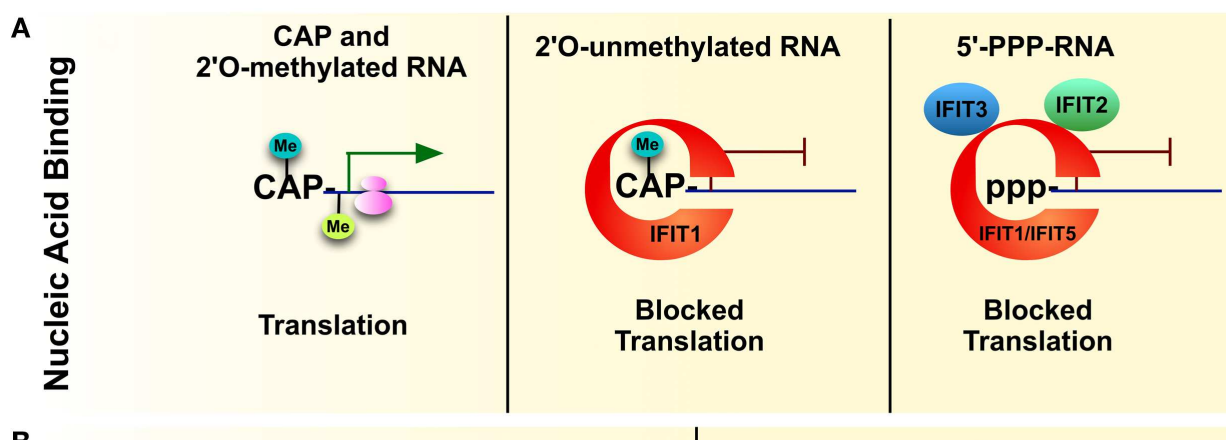

B 옹
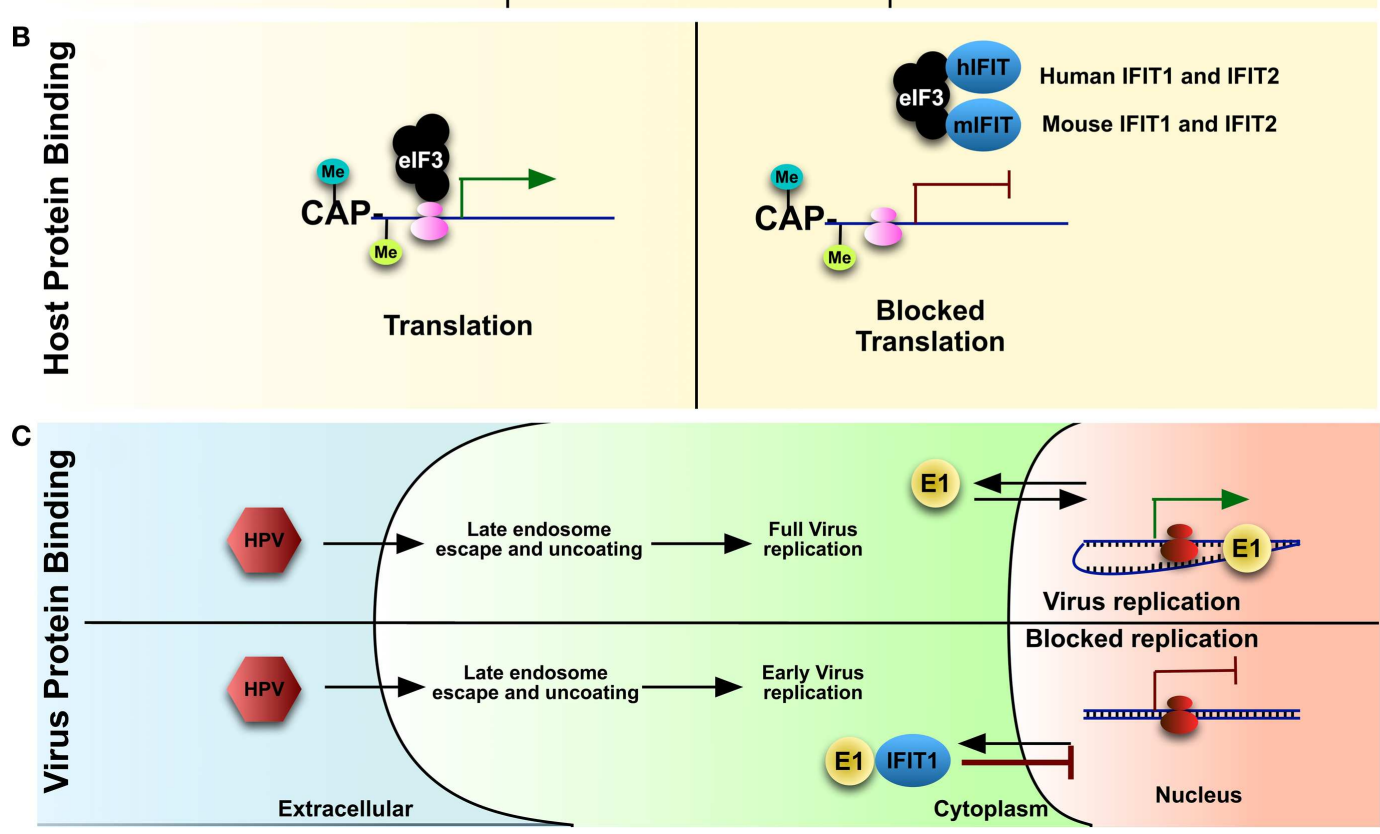

FIGURE 2 | IFITs, once upregulated due to IFN signaling, play various roles in blocking virus and host protein translation. IFIT1 can bind to the (A) 5' of mis-modified RNA either which is 2'-O-unmethylated or has 5'PPP-RNA (features of foreign nucleic acid) vs. properly capped host mRNA. IFIT1, along with a complex of IFIT2 and IFIT3, can block translation of these nucleic acids. Multiple IFITs have been described to bind to various subunits of host (B) elF3, a key component of mRNA translation. Though the target of elF3 is properly processed mRNA, including host mRNA, IFIT1 may block translation cell-wide during virus infection. As well, IFIT1 can bind (C) a key virulence factor of HPV, helicase $\mathrm{E} 1$, and sequester it into the cytoplasm, thereby preventing virus replication. papillomavirus (HPV), which is required for replication $(42,43)$. IFIT1 binds E1 and sequesters it within the cytoplasm, preventing it from aiding in viral replication within nucleus (Figure 2C). This was supported using a HPV virus expressing an E1 helicase with a deleted F399amino acid residue, which was required for IFIT1 binding; the resulting virus had no loss of replication (43).

\section{IFIT ROLE IN ANTI-VIRAL SIGNAL PATHWAY TRANSDUCTION} As well as being described as effector proteins in anti-viral replication, IFITs may also control downstream signaling, though some controversies exist. Pichlmair et al., who originally described the role of IFIT1 in binding PPP-RNA, noticed no decrease in type 1 IFNs produced in mouse fibroblasts, macrophages, or dendritic cells lacking IFIT1 (13). Later, IFIT1 was proposed as one of many innate immune "bottlenecks" and that the knocking down of IFIT1 resulted in decreased pro-inflammatory responses after LPS treatment of cells (44). In determining IFIT-mediated immune pathways, a role for IFIT3 to interact with TBK1 (TNFR-associated factor family member-associated NF- $\mathrm{B}$ activator-binding kinase 1), an important innate immune modulating kinase (45), was outlined. This interaction of IFIT3 with TBK1 bridges the kinase with mitochondrial anti-viral signaling (MAVS) on mitochondria; over-expression or knock down of IFIT3 resulted in the increase or decrease of anti-viral gene expression, respectively.

In contrast, groups have also reported immune suppressive function of IFITs. By over-expressing IFIT2 in mouse macrophages, Berchtold et al. observed reduced LPS-induced expression of multiple pro-inflammatory cytokines including TNF and IL-6 (46). This was associated with reduced mRNA stability of the cytokine transcripts in the presence of increased IFIT2, suggesting post-transcriptional regulation of inflammatory responses (46). This phenomenon, however, could be due to the natural function of IFIT family members to bind RNA and therefore an over-expression could cause intrinsic cellular issues, as well 
as cell growth defects (47). Furthermore, IFIT1 and IFIT2 were proposed to interact with stimulator of IFN genes (STING) (48), which recruits TBK1 (described above to bind IFIT3 by Liu et al.) and propagates phosphorylation of the transcription factor IRF3 (IFN regulatory transcription factor 3 ), activation of $N F-\kappa B$, and IFN production together with MAVS $(49,50)$. However, in this case, over-expression of IFIT1 in HEK cells resulted in a decrease of IRF3 activation and IFN $\beta$ promoter activation in response to Sendai virus. Here, IFIT1 was described to disrupt the interaction of STING with MAVS or TBK1 (48). Given the conflicting results in pathway propagation and downstream immunological effects, more investigative work must be done on the individual IFITs, both in vitro and in vivo, in order to draw conclusions. Moreover, the extensive characterization of protein complexes formed by IFIT family members in various cell lines using affinity purification and mass spectrometry has failed to confirm any of these interactions.

\section{CONCLUSION}

The IFIT family of proteins has recently been described as major players in anti-viral innate immunity, and their huge cellular abundance within the cell after ISG induction underscores their importance. Currently, the molecular mechanism for which highresolution structure evidence exists, clearly defines a mechanistic role of IFITs by binding to foreign nucleic acid: interfering with viral processes, which expose a foreign $5^{\prime}$ configurations of RNA, such as protein translation. However, more work must be focused on determining the fate of the bound RNA: Are IFITs trafficking foreign nucleic acid for destruction, or is the natural turnover of IFIT naturally ridding the cell of foreign material? Moreover, greater detailed investigation of IFIT effect on host-translational machinery could lead to understanding of IFIT function in absence of virus infection. Following-up on these unanswered questions will better allow us to harness the potential activity of IFITs for anti-viral treatments by exploiting the direct effect of halting transcription of foreign nucleic acid, independently of sequence.

\section{ACKNOWLEDGMENTS}

The authors apologize to those whose citations and work were excluded due to space limitations. This work was supported by the Austrian Academy of Sciences, the i-FIVE ERC grant to GSF, and EMBO LTF1543-2012 to GIV. We thank Berend Snijder, Cara West, and the GSF lab for critical reading of the manuscript.

\section{REFERENCES}

1. Takeuchi O, Akira S. Recognition of viruses by innate immunity. Immunol Rev (2007) 220:214-24. doi:10.1111/j.1600-065X.2007.00562.x

2. Vladimer GI, Marty-Roix R, Ghosh S, Weng D, Lien E. Inflammasomes and host defenses against bacterial infections. Curr Opin Microbiol (2013) 16(1):23-31. doi:10.1016/j.mib.2012.11.008

3. Janeway CA, Medzhitov R. Innate immune recognition. Annu Rev Immunol (2002) 20:197-216. doi:10.1146/annurev.immunol.20.083001.084359

4. Kawai T, Akira S. The role of pattern-recognition receptors in innate immunity: update on Toll-like receptors. Nat Immunol (2010) 11:373-84. doi:10.1038/ni. 1863

5. Rathinam VAK, Fitzgerald KA. Innate immune sensing of DNA viruses. Virology (2011) 411:153-62. doi:10.1016/j.virol.2011.02.003

6. Hornung V, Ablasser A, Charrel-Dennis M, Bauernfeind F, Horvath G, Caffrey DR, et al. AIM2 recognizes cytosolic dsDNA and forms a caspase-1-activating inflammasome with ASC. Nature (2009) 458:514-8. doi:10.1038/nature07725
7. Rathinam VAK, Jiang Z, Waggoner SN, Sharma S, Cole LE, Waggoner L, et al. The AIM2 inflammasome is essential for host defense against cytosolic bacteria and DNA viruses. Nat Immunol (2010) 11:395-402. doi:10.1038/ni.1864

8. Unterholzner L, Keating SE, Baran M, Horan KA, Jensen SB, Sharma S, et al. IFI16 is an innate immune sensor for intracellular DNA. Nat Immunol (2010) 11:997-1004. doi:10.1038/ni.1932

9. Bürckstümmer T, Baumann C, Blüml S, Dixit E, Dürnberger G, Jahn H, et al. An orthogonal proteomic-genomic screen identifies AIM2 as a cytoplasmic DNA sensor for the inflammasome. Nat Immunol (2009) 10:266-72. doi:10.1038/ni.1702

10. Barbalat R, Ewald SE, Mouchess ML, Barton GM. Nucleic acid recognition by the innate immune system. Annu Rev Immunol (2011) 29:185-214. doi:10.1146/annurev-immunol-031210-101340

11. Pichlmair A, Sousa CRE. Innate recognition of viruses. Immunity (2007) 27(3):370-83. doi:10.1016/j.immuni.2007.08.012

12. Theofilopoulos AN, Baccala R, Beutler B. Type I interferons $(\alpha / \beta)$ in immunity and autoimmunity. Annu Rev Immunol (2005) 23(1):307-36. doi:10.1146/ annurev.immunol.23.021704.115843

13. Pichlmair A, Lassnig C, Eberle C-A, Górna MW, Baumann CL, Burkard TR, et al. IFIT1 is an antiviral protein that recognizes 5'-triphosphate RNA. Nat Immunol (2011) 12:624-30. doi:10.1038/ni.2048

14. Diamond MS, Farzan M. The broad-spectrum antiviral functions of IFIT and IFITM proteins. Nat Rev Immunol (2013) 13:46-57. doi:10.1038/nri3344

15. Fensterl V, Sen GC. The ISG56/IFIT1 gene family. J Interferon Cytokine Res (2011) 31:71-8. doi:10.1089/jir.2010.0101

16. Sarkar SN, Sen GC. Novel functions of proteins encoded by viral stressinducible genes. Pharmacol Ther (2004) 103:245-59. doi:10.1016/j.pharmthera. 2004.07.007

17. Habjan M, Hubel P, Lacerda L, Benda C, Holze C, Eberl CH, et al. Sequestration by IFIT1 impairs translation of 2'O-unmethylated capped RNA. PLoS Pathog (2013) 9:e1003663. doi:10.1371/journal.ppat.1003663

18. Zhou X, Michal JJ, Zhang L, Ding B, Lunney JK, Liu B, et al. Interferon induced IFIT family genes in host antiviral defense. Int J Biol Sci (2013) 9:200-8. doi:10.7150/ijbs.5613

19. Liu Y, Zhang Y-B, Liu T-K, Gui J-F. Lineage-specific expansion of IFIT gene family: an insight into coevolution with IFN gene family. PLoS One (2013) 8(6):e66859. doi:10.1371/journal.pone.0066859

20. Terenzi F, Hui DJ, Merrick WC, Sen GC. Distinct induction patterns and functions of two closely related interferon-inducible human genes, ISG54 and ISG56. J Biol Chem (2006) 281:34064-71. doi:10.1074/jbc.M605771200

21. Terenzi F, White C, Pal S, Williams BRG, Sen GC. Tissue-specific and inducerspecific differential induction of ISG56 and ISG54 in mice. J Virol (2007) 81(16):8656-65. doi:10.1128/JVI.00322-07

22. Abbas YM, Pichlmair A, Górna MW, Superti-Furga G, Nagar B. Structural basis for viral 5'-PPP-RNA recognition by human IFIT proteins. Nature (2013) 494(7435):60-4. doi:10.1038/nature11783

23. Katibah GE, Lee HJ, Huizar JP, Vogan JM, Alber T, Collins K. tRNA binding, structure, and localization of the human interferon-induced protein IFIT5. Mol Cell (2013) 49:743-50. doi:10.1016/j.molcel.2012.12.015

24. Feng F, Yuan L, Wang YE, Crowley C, Lv Z, Li J, et al. Crystal structure and nucleotide selectivity of human IFIT5/ISG58. Cell Res (2013) 23(8):1055-8. doi:10.1038/cr.2013.80

25. Sen GC, Fensterl V. Crystal structure of IFIT2 (ISG54) predicts functional properties of IFITs. Cell Res (2012) 22:1407-9. doi:10.1038/cr.2012.130

26. Gebauer F, Hentze MW. Molecular mechanisms of translational control. Nat Rev Mol Cell Biol (2004) 5:827-35. doi:10.1038/nrm1488

27. Topisirovic I, Svitkin YV, Sonenberg N, Shatkin AJ. Cap and cap-binding proteins in the control of gene expression. Wiley Interdiscip Rev RNA (2010) 2:277-98. doi:10.1002/wrna.52

28. Hornung V, Ellegast J, Kim S, Brzózka K, Jung A, Kato H, et al. 5'-Triphosphate RNA is the ligand for RIG-I. Science (2006) 314:994-7. doi:10.1126/science. 1132505

29. Pichlmair A, Schulz O, Tan CP, Näslund TI, Liljeström P, Weber F, et al. RIGI-mediated antiviral responses to single-stranded RNA bearing 5'-phosphates. Science (2006) 314:997-1001. doi:10.1126/science.1132998

30. Fensterl V, Wetzel JL, Ramachandran S, Ogino T, Stohlman SA, Bergmann CC, et al. Interferon-induced Ifit2/ISG54 protects mice from lethal VSV neuropathogenesis. PLoS Pathog (2012) 8:e1002712. doi:10.1371/journal.ppat.1002712 
31. Schmeisser H, Mejido J, Balinsky CA, Morrow AN, Clark CR, Zhao T, et al. Identification of alpha interferon-induced genes associated with antiviral activity in Daudi cells and characterization of IFIT3 as a novel antiviral gene. J Virol (2010) 84:10671-80. doi:10.1128/JVI.00818-10

32. Zust R, Cervantes-Barragan L, Habjan M, Maier R, Neuman BW, Ziebuhr J, et al. Ribose 2'-O-methylation provides a molecular signature for the distinction of self and non-self mRNA dependent on the RNA sensor Mda5. Nat Immunol (2011) 12:137-43. doi:10.1038/ni.1979

33. Daffis S, Szretter KJ, Schriewer J, Li J, Youn S, Errett J, et al. 2'-O methylation of the viral mRNA cap evades host restriction by IFIT family members. Nature (2010) 468:452-6. doi:10.1038/nature09489

34. Szretter KJ, Daniels BP, Cho H, Gainey MD, Yokoyama WM, Gale M, et al. 2'-O methylation of the viral mRNA cap by West Nile virus evades ifit1-dependent and -independent mechanisms of host restriction in vivo. PLoS Pathog (2012) 8:e1002698. doi:10.1371/journal.ppat.1002698

35. Kimura T, Katoh H, Kayama H, Saiga H, Okuyama M, Okamoto T, et al. Ifit inhibits Japanese encephalitis virus replication through binding to 5' capped 2'O unmethylated RNA. J Virol (2013) 87:9997-10003. doi:10.1128/JVI.00883-13

36. Kumar P, Sweeney TR, Skabkin MA, Skabkina OV, Hellen CUT, Pestova TV. Inhibition of translation by IFIT family members is determined by their ability to interact selectively with the 5'-terminal regions of cap0-, cap1- and 5'pppmRNAs. Nucleic Acids Res (2013). doi:10.1093/nar/gkt1321

37. Merrick WC. Cap-dependent and cap-independent translation in eukaryotic systems. Gene (2004) 332:1-11. doi:10.1016/j.gene.2004.02.051

38. Hui DJ. Viral stress-inducible protein p56 inhibits translation by blocking the interaction of eIF3 with the ternary complex eIF2.GTP.Met-tRNAi. J Biol Chem (2003) 278:39477-82. doi:10.1074/jbc.M305038200

39. Terenzi F, Pal S, Sen GC. Induction and mode of action of the viral stressinducible murine proteins, P56 and P54. Virology (2005) 340:116-24. doi:10. 1016/j.virol.2005.06.011

40. Hui DJ, Terenzi F, Merrick WC, Sen GC. Mouse p56 blocks a distinct function of eukaryotic initiation factor 3 in translation initiation. J Biol Chem (2005) 280:3433-40. doi:10.1074/jbc.M406700200

41. Wang C, Pflugheber J, Sumpter R, Sodora DL, Hui D, Sen GC, et al. Alpha interferon induces distinct translational control programs to suppress hepatitis C virus RNA replication. J Virol (2003) 77(7):3898-912. doi:10.1128/JVI.77.7. 3898-3912.2003

42. Terenzi F, Saikia P, Sen GC. Interferon-inducible protein, P56, inhibits HPV DNA replication by binding to the viral protein E1. EMBO J (2008) 27:3311-21. doi:10.1038/emboj.2008.241
43. Saikia P, Fensterl V, Sen GC. The inhibitory action of P56 on select functions of E1 mediates interferon's effect on human papillomavirus DNA replication. J Virol (2010) 84:13036-9. doi:10.1128/JVI.01194-10

44. McDermott JE, Vartanian KB, Mitchell H, Stevens SL. Identification and validation of Ifit1 as an important innate immune bottleneck. PLoS One (2012) 7(6):e36465. doi:10.1371/journal.pone.0036465

45. Liu X-Y, Chen W, Wei B, Shan Y-F, Wang C. IFN-induced TPR protein IFIT3 potentiates antiviral signaling by bridging MAVS and TBK1. J Immunol (2011) 187:2559-68. doi:10.4049/jimmunol.1100963

46. Berchtold S, Manncke B, Klenk J, Geisel J, Autenrieth IB, Bohn E. Forced IFIT-2 expression represses LPS induced TNF-alpha expression at posttranscriptional levels. BMC Immunol (2008) 9:75. doi:10.1186/1471-2172-9-75

47. Stawowczyk M, Van Scoy S, Kumar KP, Reich NC. The interferon stimulated gene 54 promotes apoptosis. J Biol Chem (2011) 286(9):7257-66. doi:10.1074/ jbc.M110.207068

48. Li Y, Li C, Xue P, Zhong B, Mao AP, Ran Y, et al. ISG56 is a negative-feedback regulator of virus-triggered signaling and cellular antiviral response. Proc Natl Acad Sci USA (2009) 106:7945-50. doi:10.1073/pnas.0900818106

49. Ishikawa H, Barber GN. STING is an endoplasmic reticulum adaptor that facilitates innate immune signalling. Nature (2008) 455:674-8. doi:10.1038/ nature07317

50. Paludan SR, Bowie AG. Immune sensing of DNA. Immunity (2013) 38(5):870-80. doi:10.1016/j.immuni.2013.05.004

Conflict of Interest Statement: The authors declare that the research was conducted in the absence of any commercial or financial relationships that could be construed as a potential conflict of interest.

Received: 19 December 2013; accepted: 23 February 2014; published online: 10 March 2014.

Citation: Vladimer GI, Górna MW and Superti-Furga G (2014) IFITs: emerging roles as key anti-viral proteins. Front. Immunol. 5:94. doi: 10.3389/fimmu.2014.00094 This article was submitted to Molecular Innate Immunity, a section of the journal Frontiers in Immunology.

Copyright (0) 2014 Vladimer, Górna and Superti-Furga. This is an open-access article distributed under the terms of the Creative Commons Attribution License (CC BY). The use, distribution or reproduction in other forums is permitted, provided the original author(s) or licensor are credited and that the original publication in this journal is cited, in accordance with accepted academic practice. No use, distribution or reproduction is permitted which does not comply with these terms. 